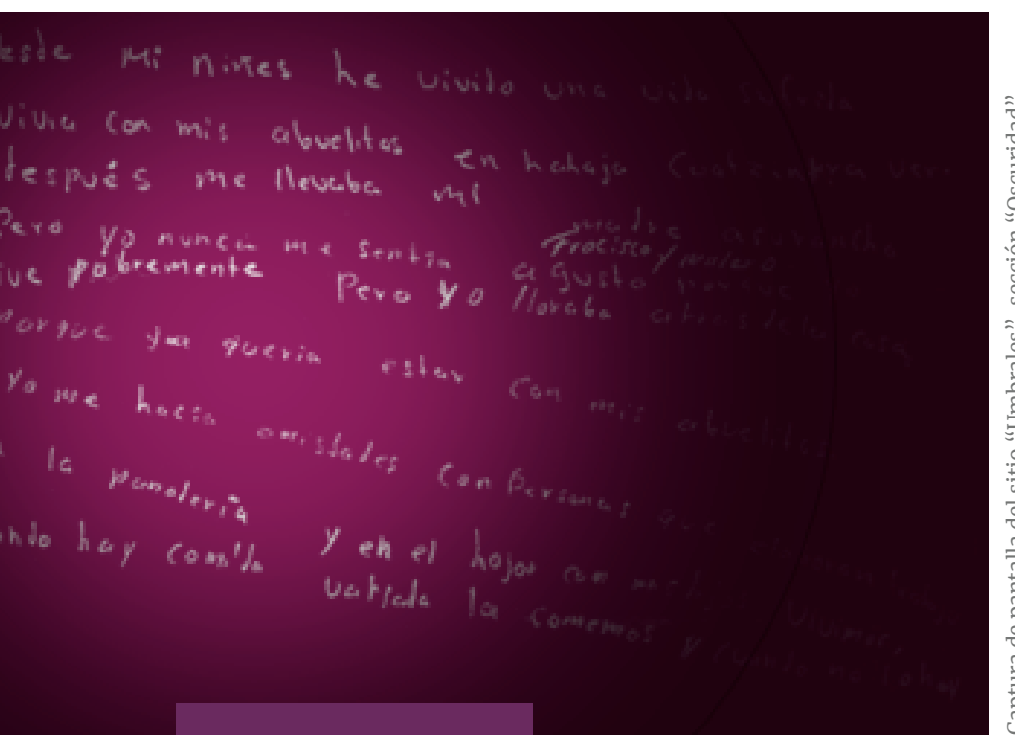

FIGURAS REVISTA ACADÉMICA DE INVESTIGACIÓN ISSN 2683-2917

Vol. 1, núm. 2, marzo-junio 2020

https://doi.org/10.22201/fesa.figuras.2020.1.2

Esta obra está bajo una licencia

Creative Commons Atribución-NoComercial-

Compartirlgual 4.0 Internacional

\section{La cultura digital y la literatura}

Fernando Didier Terrazo Pereda

https://doi.org/10.22201/fesa.figuras.2020.1.2.111

Las relaciones intermediales entre el arte y la cultura digital se desarrollan en dos planos: el físico, dentro de los espacios dedicados a la difusión, producción e investigación; y el digital, las páginas web, blogs, medios digitales y la producción en sí misma, como la Antología de poesía electrónica que el Centro de Cultura Digital (CCD) tiene en su acervo electrónico.

Esta antología consta de varias piezas que toman como principio las posibilidades multimodales que tiene la poesía para extender sus fronteras hasta ilimitadas expresiones, como presentar su recurso (la palabra) según la afinidad que le faciliten los medios, el soporte o la plataforma.

Una muestra de ello es la pieza "Desbordar" de Nadia Cortés, donde el texto se va construyendo conforme el lector arrastre el cursor sobre un cuadro blanco. Este ejercicio poético me permitió observar, entre otras manifestaciones, cómo la poesía mudó de elementos abstractos a intangibles para formular junto con los materiales que le propone el instante de esta época digital sus nuevos contornos, los cuales, en el CCD, se amplían de manera constante.

De manera oficial, el domingo 16 de septiembre de 2012 fue inaugurado este Centro en el sótano de la infamada "Estela de luz"; se encierra, entre vidrios y escalones, este espacio físico y digital dedicado a la difusión e investigación de los alcances que tiene la tecnología digital en la cultura, la economía, la sociedad y el arte.

Lo que me trajo a este lugar fue mi inclinación por la literatura experimental y las labores que el CCD ha realizado como crisol de la cultura digital. Como planes futuros, pretendo hacer una investigación crítica de las diversas aproximaciones de la poesía y los medios digitales $\mathrm{y}$, si bien ahí no encontré teorías o términos sistémicos que ayudaran a mi investigación, sí hallé una gran variedad de piezas que pueden convertirse en material para el futuro de la poesía digital y, asimismo, experimentos que proponen diluir las fronteras de la poesía (o lo que conocemos como poesía) y resignificar su quehacer cultural.

Más que un espacio para investigar, es un lugar que impulsa la investigación a través de sus exposiciones y talleres, como el proyecto de E-Literatura, por medio del cual suben, de manera virtual, los más recientes ensambles literarios digitales, piezas de autores mexicanos que con dificultad podrían encontrar difusión fuera de este sitio.

El paradigma de la literatura está en un universo que descubre constelaciones según la época que le toca vivir, a nosotros nos toca la digitalización como materia, entre otros factores, dentro de la estructura de las expresiones artísticas y la literatura, como las piezas expuestas en E-Literatura.

Además de la Antología de poesía electrónica, se encuentran obras relevantes e interesantes como los 
"Concretoons", juegos que ponen y enuncian como principio la descomposición de la poesía, la espacialidad y el movimiento para rendir un merecido tributo a los concretistas; o la narración poco usual en "Tatuajes", donde el lector descubre la historia y sus caminos de manera interactiva, como en un videojuego. Obras ricas en la experimentación y las nuevas rupturas que proponen.

\section{La experimentación artística} es tan vasta como la producción de obras; en la historia del arte y la literatura, se ha tratado de definir lo que hace a una obra ser obra y, en nuestro caso, lo que hace a la poesía ser poesía.

¿Qué hace a estas piezas ser o no literatura? La tarea del CCD es la de exponerlas, más no la de explicarlas. Cada una de las obras está acompañada de una descripción que, a modo de sinopsis, indica lo que el espectador encontrará. Por ejemplo: "Esta pieza pretende ser [sic] a invitación a borrar los límites para ponernos en el lugar, la mente y el corazón del otro." El nombre de la pieza es "Umbrales", ${ }^{1}$ una pieza creada con textos "escritos por internos del pabellón psiquiátrico Emil Kraepelin del Instituto Nacional de Neurología y Neurocirugía Manuel Velasco Suárez". ${ }^{2}$

La entrada a la pieza se divide en cuatro esferas con títulos centrados "Futuro", "Luz", "Oscuridad"

${ }^{1}$ Yolanda de la Torre, E-Literatura (México: Umbrales, 2015). http://www.umbrales.mx/ Revisado el 29 de diciembre, 2019

2 s/n s/f México: Centro de Cultura Digital. http://editorial. centroculturadigital.mx/eliteratura Revisado el 29 de diciembre, 2019. y "Pasado". Cada una de ellas lleva a una página nueva con contenido distinto en otra pantalla. En la esfera "Futuro" se oculta la frase: "Todos imaginamos, dibujamos el futuro. El futuro es hoy un trazo, un nombre, una carta". Debajo de la frase hay un recuadro blanco en el que uno puede trazar el futuro que le convenga.

Una metáfora entre el porvenir y su construcción, donde el destino no existe y el futuro es una mera aproximación del presente en la que intervienen la decisión y la posibilidad de lo que el usuario crea dentro del espacio que se le asigna. Pero, ¿esta metáfora termina por ensamblar los elementos de la obra con las características de la literatura? De ser así, es otra forma de consumir literatura; de lo contrario, si no es literatura ¿qué es? Demos por sentado que es literatura, porque así el autor ha denominado su obra y porque está en la sección electrónica de literatura en el CCD, lugar de donde cualquier usuario lo puede tomar y, por lo mismo, cuestionar y volver a su hechura literaria. Por supuesto que el espectador buscará anclar su concepto de literatura sobre esa obra o su concepto de poesía sobre esas piezas, lo que me hace preguntarme, ¿en realidad esta poesía electrónica y literatura está ahí para todo el público?

La experimentación artística es tan vasta como la misma producción de obras; si revisamos la historia del arte y la literatura, se ha tratado de definir (sin poner límites, pero sí deslindando conceptos) lo que hace a una obra ser obra y, en nuestro caso, lo que hace a la poesía ser poesía (ese algo que en realidad continúa en desarrollo según "las etapas temporales"). Pero ¿qué pasaría si optaran por anteponer otro mote que no sea "literatura" o "poesía"? Un caso muy cercano a nuestro interés se suscitó en 1958 con el Pabellón Philips de la Feria Internacional de Bruselas. Un edificio realizado (y poco mencionado) por Le Corbusier que, en conjunto con la música a cargo de Edgar Varèse, proyecciones de Jean Petit y Philippe Agostini y colaboración de 
Iannis Xenakis, nombraron "Poème électronique" (Poema electrónico). ${ }^{3}$

\section{Las obras expuestas en el CCD quiebran cualquier concepto de literatura, resignifican la pieza en tanto que poema y recuerdan experimentaciones vanguardistas con actualizaciones tecnológicas.}

Con la idea de realizar la primera exposición internacional de arte en Bruselas después de la II Guerra Mundial, los arquitectos y artistas quisieron resaltar el renacimiento de la nueva civilización, llevando a cabo un ejercicio que nunca nadie había hecho, una obra que sintetizara la búsqueda de remontar la cultura europea tras la guerra. Por lo que asieron las novedades culturales y tecnológicas de sus especialidades para tejer con ellas el concepto del "Poème électronique". Varèse tenía un criterio sonoro que evitaba ajustarse a alguna taxonomía conocida y con resquemores alejarse de los cánones musicales, el cual convenía a la propuesta del "Poème électronique", obras que no clasificaba como música y que nombró "son organisée" 4 (sonido organizado).

3 Un texto muy completo sobre el Poème électronique se puede encontrar en el siguiente enlace: https://scielo. conicyt.cl/scielo.php?script=sci arttext\&pid=S071769962006000200013\&fbclid=IwAR2K4DSo057KeMXo nhC9i8T510I9HYFHiAnOXnzWglqh6HFmeYJ9xaOhvl8 Revisado el 03 de enero, 2019.

4 Nicholas C. Laudadio Given, "Organized Sound, Unbounded Space: Edgard Varèse, Poème Électronique, and the Wondrous Promise of Midcentury Soundscapes at the 2016 IAFA" (Conferencia presentada en IAFA Orlando, Florida, 2016). Se puede consultar la conferencia completa en: https://www.academia.edu/26931516/ Organized Sound Unbounded Space Edgard Var\%C3\%A8se Po\%C3\%A8me \%C3\%89lectronique and the Wondrous Promise of Midcentury Soundscapes Revisado el 29 de enero, 2019.
Las obras expuestas en el CCD quiebran cualquier concepto de literatura, resignifican la pieza en tanto que poema, recuerdan experimentaciones vanguardistas con actualizaciones tecnológicas, por lo que ¿por qué no ir con osadía más allá de la experiencia creadora y proponer una teoría pragmática que explique la obra como hecho ficcional y nombrarla en un apartado distinto genérico?, ¿acaso el mote "literatura" o "poesía" en los umbrales de la obra funge con autoridad sobre su criterio o recepción?

Dentro de las instalaciones del CCD (física y virtual) no se halla una respuesta para resolver estas dudas; todo lo contrario, uno encuentra más preguntas sobre la relación de la tecnología digital con la cultura, la sociedad, la economía, el arte y la literatura, y quizá ese es su propósito: proponer las cuestiones para rastrear el futuro tecnológico y su correspondencia con el ser humano.

Así que, como un centro de investigación, propone la constante actualización de los principios digitales y su desarrollo a niveles culturales a través de exposiciones, juegos, conferencias, laboratorios, interacciones y actividades que, dicho sea de paso, son caminos amplios para continuar la investigación social de la cultura digital en la cotidianidad.

\section{Referencias}

Laudadio Given, Nicholas C., "Organized Sound, Unbounded Space: Edgard Varèse, Poème Électronique, and the Wondrous Promise of Midcentury Soundscapes at the 2016 IAFA." Conferencia presentada en IAFA, Orlando, Florida, 2016. https:// www.academia.edu/26931516/Organized_Sound_ Unbounded_Space_Edgard_Var\%C3\%A8se Po\%C3\%A8me \%C3\%89lectronique and the Wondrous Promise of Midcentury Soundscapes

Torre, Yolanda de la. E-Literatura. México: Umbrales, 2016. http://www.umbrales.mx/ 